\title{
Performance of Un-coded MC-CDMA-based Broadband Power Line Communications
}

\author{
Daniel Ngondya \\ School of Informatics, \\ University of Dodoma
}

\author{
Justinian Anatory \\ School of Informatics, \\ University of Dodoma
}

\author{
Abdil Rashid Mohamed \\ Department of Computer \\ Science and Engineering, \\ University of Dar es Salaam
}

\begin{abstract}
Physical and noise characteristics of power line network have made it a challenging task to design Broadband Power Line Communication (BPLC) systems using single carrier systems. Multicarrier schemes such as Orthogonal Frequency Division Multiplexing (OFDM) have been widely used to design the systems. However, recently Multicarrier Code Division Multiple Access (MC-CDMA) which combines the best features of OFDM and Code Division Multiple Access (CDMA) has been gaining popularity. In this work, a typical low-voltage power-line network found in Kariakoo Area, Dar es Salaam has been considered. Performance of such a lowvoltage channel using Multi-Carrier Code Division Multiple Access with Binary Phase Shift Keying (BPSK) modulation has been assessed for suitability to communication. The simulation of the power-line network was based on data collected from a Map of Kariakoo power-line network. Document Analysis techniques were used to identify branches, cable types, and segment lengths from the map. In the simulated network, the positions of transmitter and receivers were varied to identify possible degraded performance scenarios. It was observed that the maximum Delay Spread for such networks is $3 \mu \mathrm{s}$, making the number of sub-channels and Cyclic Prefix required to build a 100MegaHertz system, 4096 and 512 respectively. The use of MC-CDMA in broadband power-line communication results in improved performance by 12 to 43 Decibels compared to the use of Orthogonal Frequency Division Multiple Access.
\end{abstract}

\section{General Terms}

Data Communications.

\section{Keywords}

MC-CDMA, Broadband Power Line Communications, Multicarrier Modulation.

\section{INTRODUCTION}

In most developing countries such as Tanzania, rural Information and Communication Technology (ICT) infrastructure is often poor because of high cost of last mile connectivity. It is estimated that building last mile infrastructure from scratch costs up to $50 \%$ of all ICT investment [2, 3]. Ubiquity of power lines provides an attractive opportunity to extend telecommunication services to the rural areas. However, power lines' characteristics such as frequency selective fading, background and impulsive noise, and time-varying channel attenuation are unfavorable to communications[4]. The characteristics require advanced signal processing techniques. It has been observed that single- carrier modulation schemes are inadequate for high speed communication, especially in frequency selective fading environments[4]. Multi-carrier modulation achieves the highest performance in channels with frequency selective fading and severe inter-symbol interference (ISI) such as the power line channel. OFDM-a multicarrier technique, has been used extensively in designing BPLC systems. However, recently, MC-CDMA has attracted the interests of researchers as it embodies the best of OFDM and CDMA.

Designing power-line communications system requires a model that adequately describes channel characteristics of power lines. Over time, a number of models based on Transmission Line Theory (TLT), Multi-conductor Transmission Line (MTL) and measurements have attempted to describe the channel. In this work, a power line channel by [1] has been used.

The rest of the paper is organized as follows: Section II presents key issues associated with BPLC, Section III presents a network design of the BPLC-based MC-CDMA System. Section IV presents the results and finally Section V draws conclusion.

\section{BROADBAND POWER LINE COMMUNICATIONS}

\subsection{Standardization of BPLC}

Power lines have been used for communication purposes for decades. However, they have not been widely accepted mainly because of lack of standardization by an authoritative and credible body[5]. In 2010, IEEE issued a standard for broadband power line communications with data rates of up to $500 \mathrm{Mbps}$ for transmission frequencies below $100 \mathrm{MHz}[6]$. The standard covers both indoor and outdoor communications.

\subsection{Power Line Channel Model}

The first significant effort to characterize power line channel was by [7]. It was a simple and straight-forward model where attenuation increased with frequency. However, the model did not take into account the effect of multipath-a feature that is commonly associated with power lines. Multipath propagation was taken into account by [8] where signals travel in several paths, each with different delays. A model presented by [9] is widely accepted as it considers multipath propagation and cable losses (see Equation 1). The model characterizes each path by a weighing factor gi (product of reflection and transmission factors) and path length di. The parameters a0, $\mathrm{a} 1$ and $\mathrm{k}$ are obtained from measurements and are used to model the attenuation factor. $\mathrm{N}$ is the number of paths. 
$H(f)=\sum_{i=1}^{N} g_{i} e^{-\left(a_{0}+a_{1} f^{k}\right) d_{i}} e^{-j 2 \pi \frac{d_{i}}{v_{p}}}$.

There have been efforts to improve the model presented by [9] by taking into consideration physical characteristics such as segments, branches and termination[10]. In this work, the power-line channel model (see Appendix) proposed by [1] which is based on TLT, has been used. The model is relatively complex, but adequately reflects physical characteristics of the power line channel as it additionally takes into account the loads, interconnection of nodes and distances between nodes.

\subsection{Noise Characteristics of PLC}

In power lines, noise can be grouped into two main types: Impulsive Noise and Generalized Background Noise[2, 11]. The former is composed of the periodic impulses that are synchronous with the main frequency and the asynchronous impulsive noise while the latter is the superposition of the coloured background noise and narrowband disturbances. The fundamental cause of error bursts associated with the PLC channel is the Impulsive noise.

In this work, an unspecified number of independent noise sources transmitting at random (in time and space) were considered. Noises were modeled using Middleton's Class A in such a way that impulsive and background noises forms a sequence of independent and identically distributed complex random variables with the Probability Density Function (pdf) of Class A noise given by Equation 2[12,13]. In the equation, $\mathrm{m}$ represents the number of impulsive noise sources characterized by Poisson distribution with mean parameter A called the Impulsive Index. The impulsive index is the product of the average rate of impulsive noise and the mean duration of a typical impulse (see Equation 3).

$\mathrm{p}_{\mathrm{z}}(\mathrm{z})=\sum_{\mathrm{m}=0}^{\infty} \frac{\alpha_{\mathrm{m}}}{\sqrt{2 \pi \sigma_{\mathrm{m}}^{2}}} \exp \left(-\frac{\mathrm{z}^{2}}{2 \sigma_{\mathrm{m}}^{2}}\right)$.

$\propto_{\mathrm{m}}=\mathrm{e}^{-\mathrm{A}} \frac{\mathrm{A}^{\mathrm{m}}}{\mathrm{m} !}$.

$\sigma_{\mathrm{m}}^{2}=\sigma_{\mathrm{g}}^{2} \frac{\left(\frac{\mathrm{m}}{\mathrm{A}}\right)+\Gamma}{\Gamma}$.

$\sigma_{\mathrm{z}}^{2}=\mathrm{E}\left\{\mathrm{z}^{2}\right\}=\frac{\mathrm{e}^{-\mathrm{A}} \sigma_{\mathrm{g}}^{2}}{\Gamma} \sum_{\mathrm{m}=0}^{\infty} \frac{\mathrm{A}^{\mathrm{m}}}{\mathrm{m} !}\left(\frac{\mathrm{m}}{\mathrm{A}}+\Gamma\right)$.

The Gauss Impulsive power Ratio (GIR)-denoted by $\Gamma$ in Equation 4 is the ratio between variance of Gaussian noise components $\sigma_{\mathrm{g}}^{2}$ and the variance of impulse components $\sigma_{\mathrm{m}}^{2}$, while in Equation $5, \sigma_{\mathrm{z}}^{2}$ is the variance of noise. For the purpose of this work, A, GIR and $m$ have been assumed to be $0.1,0.1$ and 3 respectively as suggested in $[1,14,15]$.

\subsection{BPLC Modulation}

Modulation schemes such Frequency Shift Keying (FSK), Phase Shift Keying (PSK), Gaussian Minimum Shift Keying (GMSK), Quadrature Amplitude Modulation (QAM), Spread Spectrum, OFDM and MC-CDMA have been used in PLC environments [16]. Choice of a particular modulation scheme is mainly a trade-off between performance and cost. Taking into account characteristics of PLC environment-multipath propagation and frequency selective fading; MC-CDMA has been used as a multicarrier scheme with the low throughput BPSK for subcarrier modulation.

For un-coded MC-CDMA system, at the transmitter side, modulated input data are first converted into parallel sequences and spread using schemes such as Walsh Hadamard codes, Gold codes, etc. Data in the spreading bits is baseband modulated by Inverse Fast Fourier Transform (IFFT) and then converted from parallel to serial. Before placing data sequences on the PLC channel, a guard interval is added in order to counter Inter-symbol Interference (ISI). The resulting data sequence is then transmitted by the PLC channel to the receiver, where the opposite of processing done at the transmitter occurs. Fig. 1 illustrates processing of data bits and both transmitter and receiver for un-coded MC-CDMA system.

According to [17], symbol error probability $\left(\mathrm{P}_{\mathrm{s}}\right)$ of BPSKmodulated system is given by Equation 6. For an MC-CDMA system, signal-to-noise ratio (SNR) per symbol is given by Equation 7. From Equations 6 and 7, symbol error probability $\left(\mathrm{P}_{\text {smccdma }}\right)$ of the un-coded BPSK-modulated MC-CDMA system is given by Equation 8, where $\mathrm{N}$ is the number of channels, $H_{k}(n)$ is the channel transfer function at sub-carrier $\mathrm{k}$, SNRs is the signal-to-noise per symbol, Es is the energy of per symbol, and $\mathrm{N}_{0} / 2$ is the noise power spectral density.

$P_{S}=Q\left(\sqrt{\frac{2 E_{s}}{N_{o}}}\right)$

$\mathrm{SNR}_{\mathrm{s}}=\left(\frac{1}{\mathrm{~N}} \sum_{\mathrm{k}=0}^{\mathrm{N}-1}\left|\mathrm{H}_{\mathrm{k}}(\mathrm{n})\right|^{2}\right) \frac{\mathrm{E}_{\mathrm{s}}}{\mathrm{N}_{\mathrm{o}}}$.

$P_{\text {smccdma }}=Q\left(\sqrt{2 *\left(\frac{1}{\mathrm{~N}} \sum_{k=0}^{\mathrm{N}-1}\left|\mathrm{H}_{k}(n)\right|^{2}\right) \frac{\mathrm{E}_{s}}{\mathrm{~N}_{m}}}\right)$

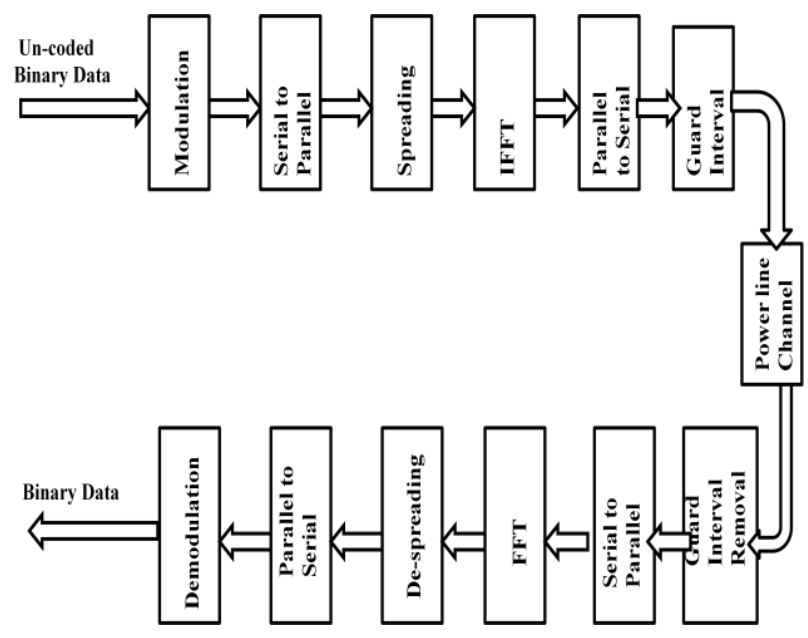

Figure 1: Un-coded MC-CDMA System over a Power line Channel

\section{NETWORK DESIGN BASED ON MC- CDMA}

\subsection{Data Collection and Analysis}

Kariakoo's Outdoor Low Voltage power line network in Dar es Salaam, Tanzania has been used to simulate MC-CDMAbased BPLC. It is an urban network with more branches and segments than a typical rural one. Figure 2 shows the map of the network. The map was used to gather regarding types of cable used, interconnections, and loads as in Table 1. Data on instantaneous behavior of the network was gathered through a simulation of the power-line network using the measurements obtained from the map. To minimize errors, cross-checking of the map using the map's Key was done. Since nodes are 
continuously added to the power-line network, it is possible that the map does not reflect the current configuration of the network. However, details available on the map are sufficient enough to draw conclusions on the suitability of MC-CDMA for BPLC. Data collected from the map was analyzed using Document Analysis techniques, where the map was studied so as to identify patterns and themes relevant to the research objectives. Types of cable used in the network, branches, and segment lengths were identified as in Table 1.

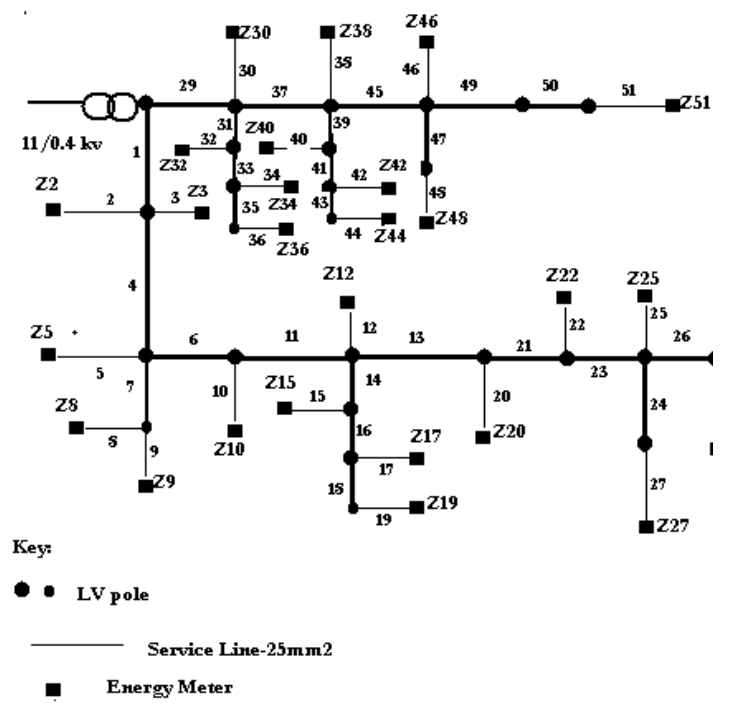

Figure 2: Power-line network configuration at Kariakoo in Dar es Salaam[1].

\subsection{Impulse Response of the Network}

Characterization of the impulse response of the network is very important in the design, development and planning of radio systems[18]; PLC being radio communication, is no exception. It is from the impulse response of the network that the Delay Spread and channel Coherence Bandwidth necessary for the network design of MC-CDMA-based on BPLC can be determined. In this work, impulse response analysis was carried out at various points in the network by taking into account distance, terminal load and branching between transmitter and receiver.

The impulse response was determined at Z2, Z9, Z19 and Z27 for network Segment A with a transmitter at $\mathrm{X}$ and branches terminated in $5 \Omega$ (see Figure 4). For Segment B (with transmitter at Y), it was determined at Z36, Z44, Z48 and Z51 and branches were terminated in $100 \mathrm{k} \Omega$ (see Figure 5). The receiving points in the two segments were terminated in their respective branch characteristic impedance. The impulse response was found using IFFT of the transfer function. A signal of $2 \mathrm{~V}$ was applied at both transmitter $\mathrm{X}$ and $\mathrm{Y}$. In both cases, it can be deduced from the Figures 4 and 5 that the maximum delay spread $\mathrm{Tm}$ is close to $3.0 \mu \mathrm{s}$.
Table 1: Line segments based on various branches

\begin{tabular}{|l|l|l|l|}
\hline Category & $\begin{array}{l}\text { Conductor } \\
\text { cross-section } \\
\text { Area }\end{array}$ & Length & Branches \\
\hline A & $100 \mathrm{~mm}^{2}$ & $40 \mathrm{~m}$ & $\begin{array}{l}1,4,6,11,13,26,29,37, \\
45,49,50\end{array}$ \\
\hline B & $50 \mathrm{~mm}^{2}$ & $40 \mathrm{~m}$ & 7 \\
\hline C & $25 \mathrm{~mm}^{2}$ & $25 \mathrm{~m}$ & $2,3,5,8,9,10,12,15,17$, \\
& & & $19,20,22,25,27$, \\
& & & $28,30,32,34,36,38,40$, \\
& & & $42,44,46,48,51$ \\
\hline D & $100 \mathrm{~mm}^{2}$ & $35 \mathrm{~m}$ & 21,23 \\
\hline E & $50 \mathrm{~mm}^{2}$ & $35 \mathrm{~m}$ & $14,16,18,24,31,33,35$, \\
& & & $39,41,43,47$ \\
& & & \\
\hline
\end{tabular}

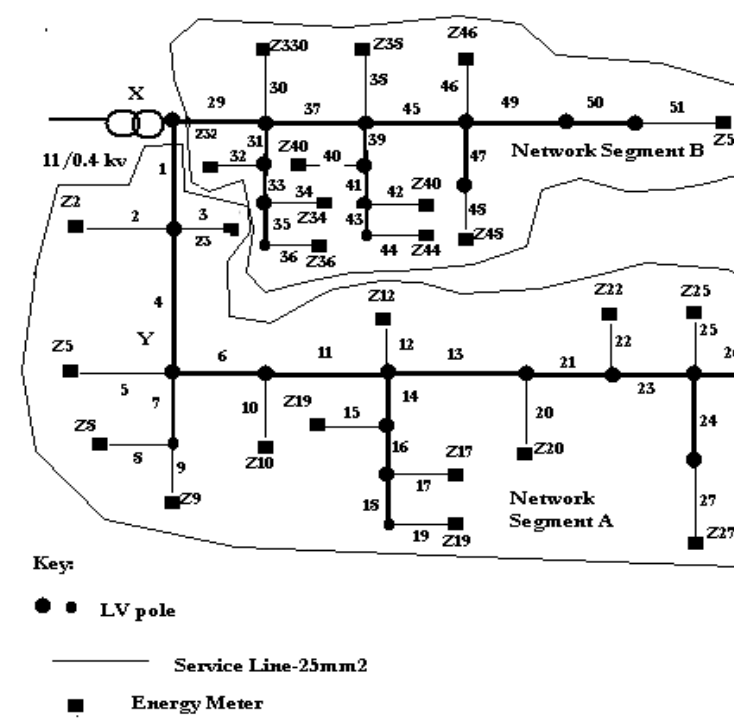

Figure 3: Network Segment A and B[1]. 

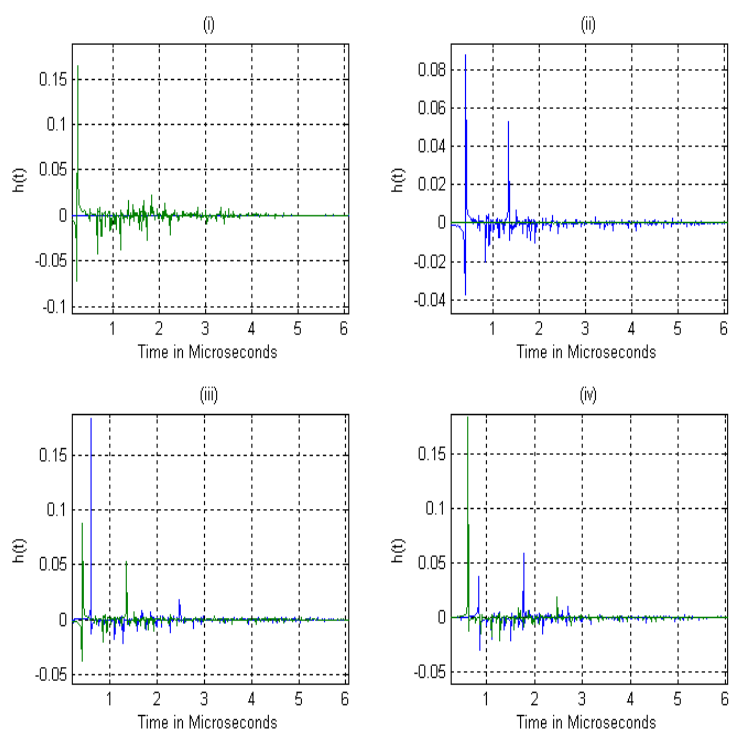

Figure 4: Impulse response in the Network Segment $A$ in Figure 3.2 at (i) $\mathrm{Z2}$ (ii) $\mathrm{Z9}$ (iii) $\mathrm{Z19}$ and (iv) $\mathrm{Z27}$ (all terminated in their branch characteristic impedances, and the rest of the terminals terminated in $5 \Omega$ ).

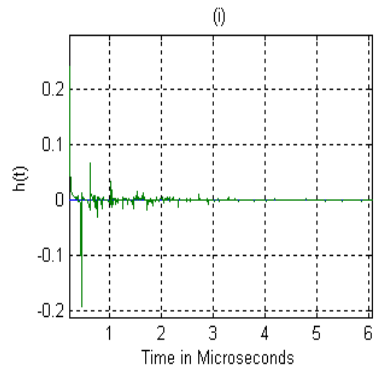

(iii)

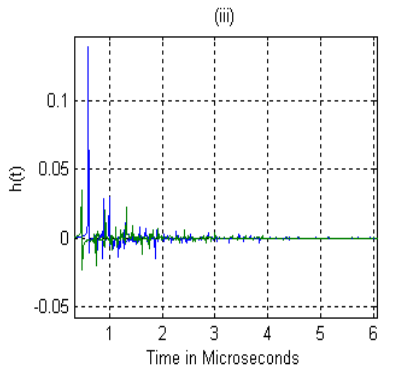

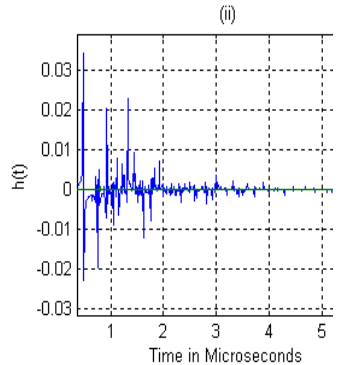

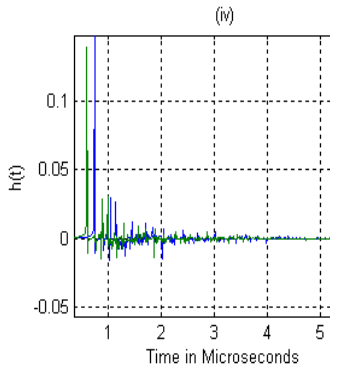

Figure 5: Impulse response for various terminals in the Network Segment B in Figure 3.2 at (i) Z36 (ii) Z44 (iii) $\mathrm{Z48}$ and (iv) $\mathrm{Z51}$ (all terminated in their characteristic impedances, and the rest terminated in $100 \mathrm{k} \Omega$ ).

\subsection{Design of the MC-CDMA System}

Multicarrier systems work by dividing available bandwidth into sub-channels; the data stream is also divided and transmitted in the sub-channels, hence making more efficient use of the bandwidth as opposed to single channel systems. An MC-CDMA system with total bandwidth of $100 \mathrm{MHz}$ and BPSK modulation for each sub-channel has been considered.

The number of sub-channels $\mathrm{N}$ has to be chosen in such a way that the Symbol Time in each sub-channel is greater than the Delay Spread of the channel so as to combat ISI. That is, sub- channel bandwidth is less than the channel coherence bandwidth. Note that, the delay spread is the time it takes for the signal to die down, whereas symbol time is the original time of the pulse. Since the maximum delay spread is $3.0 \mu$ s, the channel coherence bandwidth $\mathrm{Bc}$ is given by Equation 9:

$B_{c}=1 / T_{m}=1 / 3.0 \mu \mathrm{s}=0.333 \mathrm{MHz}$

Ensuring flat fading on each sub-channel, $\mathrm{B} / \mathrm{N}=0.1 * \mathrm{Bc}$ [19], where $\mathrm{B}$ is the total bandwidth, and $\mathrm{Bc}$ is the coherence bandwidth. The number of sub-channel $\mathrm{N}=100 \mathrm{MHz} /(0.1 * 0.333 \mathrm{MHz})=3003$. For multiplexing purposes, $\mathrm{N}$ must be a power of two, and so $\mathrm{N}$ is 4096 . It follows that MC-CDMA's symbol duration given by Equation 10:

$T N=N T_{S}=N / B=4096 / 100 * 106=40.96 \mu \mathrm{s}$

Modulation scheme's performance is reduced by transmission impairments such as fading, noise and delay spread. The delay spread is responsible for inter-symbol ISI between MCCDMA symbols[20]. The cyclic prefix $\mu$, which helps to fight ISI between the symbols, is given by Equation 11 as proposed in the IEEE 802.16 standard $[1,21]$. It can be observed that the cyclic prefix is greater than both the maximum delay spread Tm and symbol time Ts; this is so in order to suppress ISI[22, 23]. The guard interval is therefore computed by Equation 12:

$\mu=(1 / 8) * N=512$

$\mu * T_{s}=512 /(100 * 106)=5.12 \mu \mathrm{s}$.

For each sub-channel, the sub-channel bandwidth and subchannel data rate are given by Equation 13 and Equation 14 respectively as:

$\mathrm{BN}=1 / \mathrm{TN}=1 / 40.96 \mu \mathrm{s}=24.4 \mathrm{KHz}$

$R N=\left(\log _{2} M\right) /_{T N}=\left(\log _{2} M\right) /_{T N}=\left(\log _{2} 2\right) / 40.96=$

24.4Kbps.

The transmission time of each MC-CDMA symbol is $\mathrm{T}=$ $\mathrm{TN}+\mu \mathrm{Ts}=40.96+5.12=46.08 \mu \mathrm{s}$. It means that the MCCDMA system transmits $\log _{2} \mathrm{M}=1$ bit per sub-channel every $\mathrm{T}$ seconds ( $\mathrm{M}=2$ for BPSK modulation), so the data rate is $4096 * 1 /(46.08 \mu \mathrm{s})=88.89 \mathrm{Mbps}[24]$. The MC-CDMA design parameters are used with the noise modeling parameters were used to simulate the PLC. Table 2 summarizes design parameters of MC-CDMA system. 
Table 2: Design parameters for MC-CDMA system

\begin{tabular}{|l|l|}
\hline Parameter & Value \\
\hline Total Bandwidth (B) & $100 \mathrm{MHz}$ \\
\hline Coherence Bandwidth $\left(\mathrm{B}_{\mathrm{c}}\right)$ & $0.333 \mathrm{MHz}$ \\
\hline Number of Channels $(\mathrm{N})$ & 4096 \\
\hline Modulation & BPSK, MC-CDMA \\
\hline Spreading Codes & Walsh Hadamard \\
\hline $\begin{array}{l}\text { MC-CDMA Symbol } \\
\left.\text { Duration ( } \mathrm{T}_{\mathrm{N}}\right)\end{array}$ & $40.96 \mu \mathrm{s}$ \\
\hline Cyclic Prefix $(\mu)$ & 512 \\
\hline Guard Interval & $5.12 \mu \mathrm{s}$ \\
\hline Sub-channel Bandwidth $\mathrm{B}_{\mathrm{N}}$ & $24.4 \mathrm{KHz}$ \\
\hline Data Rate & $88.9 \mathrm{Mbps}$ \\
\hline
\end{tabular}

\section{PERFORMANCE EVALUATION OF UN-CODED MC-CDMA}

To assess the performance of MC-CDMA system, network Segments A and B were simulated separately. With Segment $A$, all branches were terminated in their respective characteristic impedance except Z10, Z12, Z15 and Z20 which were terminated in $50 \Omega$. In Segment B, all branches were terminated in their respective characteristic impedance except Z38 and Z46 which were terminated in $50 \Omega$.

Figure 6 indicates the performance of MC-CDMA system without error correction mechanism (un-coded) in Segment A. Point Z5 indicates the best performance (SNR 29dB at 10-10 BER) compared to Z19 and Z27 as it is closest to the transmitter. Performance at point $\mathrm{Z} 27$ is the poorest as it is farthest from the transmitter.

Figure 7 illustrates the performance of MC-CDMA system without error correction mechanisms (un-coded) in Segment B. Point Z30 indicates better performance compared to point Z44 because it is closer to the transmitter than point Z44. Generally, performance deteriorates as the distance and number of branches between the transmitter and receiver increases.

A study on the performance of the same power-line network with OFDM as a multicarrier scheme and BPSK modulation for each channel by [1] shows comparable results. In the study (see Fig. 8), performance worsens with increase in distance and number of branches between the transmitter and receiver. Moreover, the best performance for un-coded-segmented network is BER of 10-10 at SNR per bit of $47 \mathrm{~dB}$. Comparing with this study's SNR per bit of $29 \mathrm{~dB}$ at 10-10 BER, it can be argued that un-coded MC-CDMA system based on BPLC has better BER and SNR values than OFDM system based on BPLC as there is performance improvement of $16 \mathrm{~dB}$.

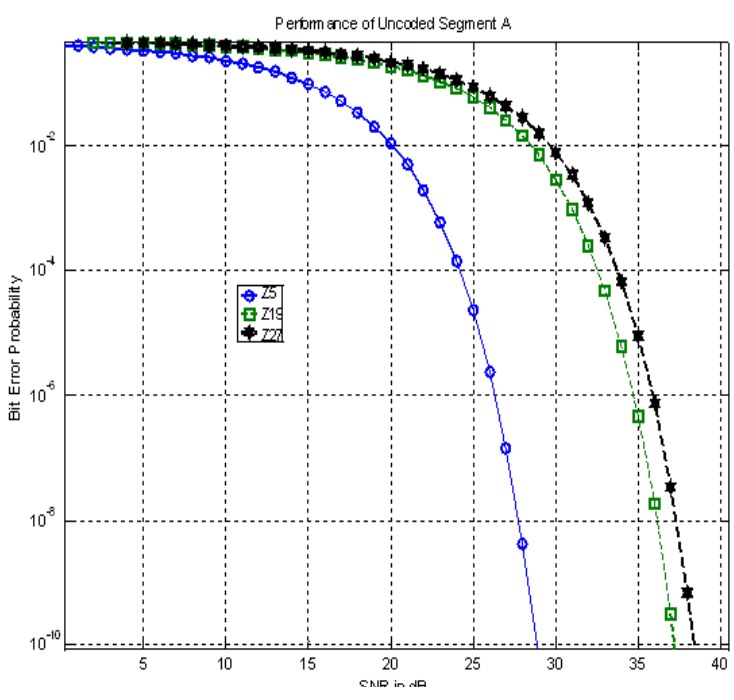

Figure 6: Performance of un-coded MC-

CDMA system with BPSK sub-carrier in a

Power-line network with Segment A simulated separately. All branches are terminated in their respective characteristic impedance except Z10, Z12, Z15 and Z20 terminated in $50 \Omega$.

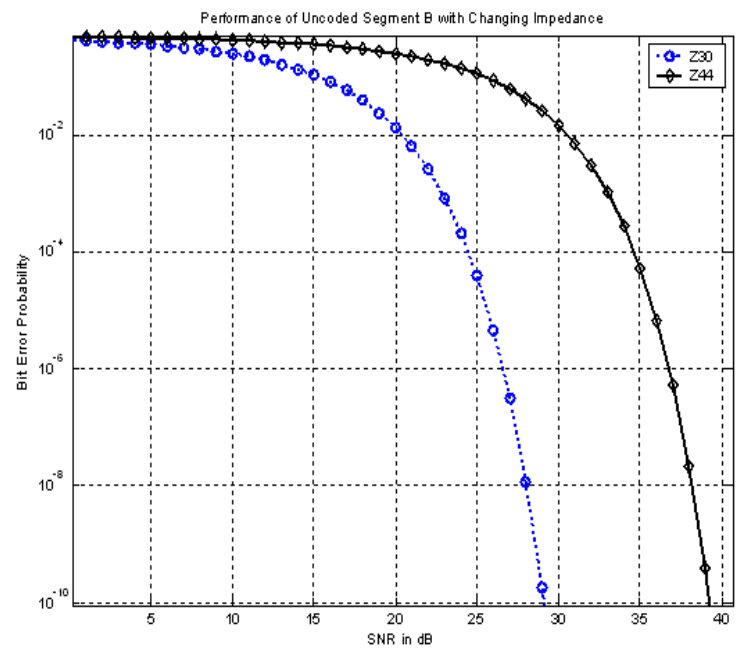

Figure 7: Performance of un-coded MC-CDMA system with BPSK sub-carrier in Segment $B$ of the power-line network with all branches terminated in their respective characteristic impedance except points $\mathrm{Z38}$ and $\mathrm{Z46}$ which were terminated in $50 \Omega$. 


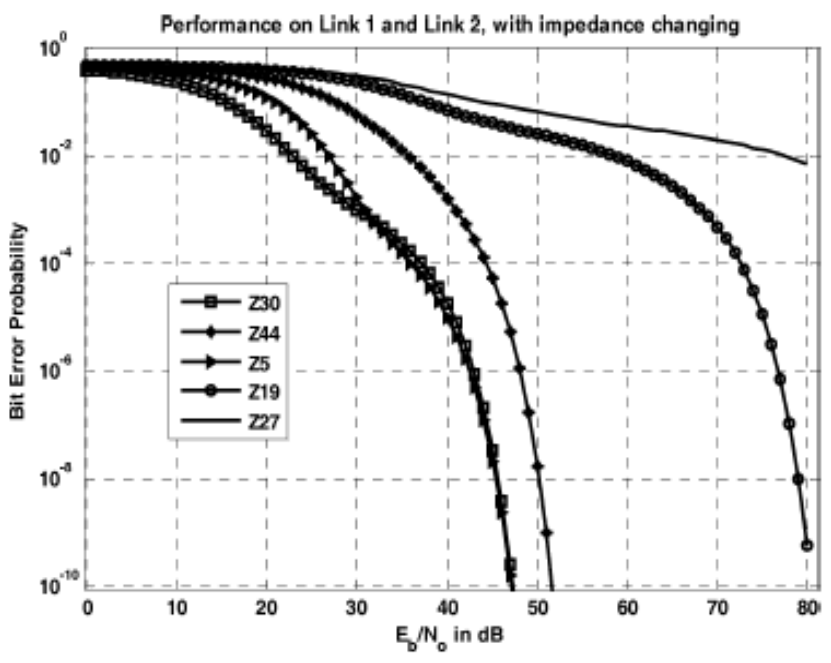

Figure 8: Performance of un-coded OFDM system with BPSK sub-carrier in a power-line network with Segment A (Link 1) and Segment B (Link 2) considered separately with all branches terminated in their respective characteristic impedance except Z10, Z12, Z15, Z20, Z38 and Z46[1]

\section{CONCLUSIONS}

In this paper, design specifications of the MC-CDMA system based on BPLC with BPSK modulation for each sub-channel have been studied. The power-line channel model was used to simulate an actual power-line network of Kariakoo in Dar-esSalaam, Tanzania. It has been observed that for such an urban network, the maximum delay spread is $3 \mu \mathrm{s}$, making the number of channels and cyclic prefix required in designing a $100 \mathrm{MHz}$ bandwidth-MC-CDMA system based on BPSK, 4096 and 512 respectively. The performance of un-coded MC-CDMA system was found to deteriorate with increase in number of branches and segment length between transmitter and receiver. The un-coded MC-CDMA system indicates performance improvement of $12-43 \mathrm{~dB}$ compared to un-coded OFDM system configured in the same manner.

\section{REFERENCES}

[1] J. Anatory, N. Theethayi, and R. Thottappillil, "Channel characterization for indoor power-line networks," Power Delivery, IEEE Transactions on, vol. 24, pp. 1883-1888, 2009.

[2] H. Hrasnica, A. Haidine, and R. Lehnert, Broadband powerline communications: network design: John Wiley \& Sons, 2005.

[3] A. Bhavnani, R. W.-W. Chiu, S. Janakiram, P. Silarszky, and D. Bhatia, "The role of mobile phones in sustainable rural poverty reduction," retrieved November, vol. 22, p. 2008, 2008.

[4] H. Dai and H. V. Poor, "Advanced signal processing for power line communications," Communications Magazine, IEEE, vol. 41, pp. 100-107, 2003.

[5] S. Galli and O. Logvinov, "Recent developments in the standardization of power line communications within the IEEE," Communications Magazine, IEEE, vol. 46, pp. 64-71, 2008.
[6] N. Arun, R. R. Purva, K. Manjunath, R. Markus, S. Matthias, and R. Deniz, "IEEE 1901," in MIMO Power Line Communications, ed: CRC Press, 2014, pp. 357 390.

[7] C. Hensen and W. Schulz, "High rate data communication via power distribution network using DS-CDMA technique," in Universal Personal Communications Record, 1997. Conference Record., 1997 IEEE 6th International Conference on, 1997, pp. 805-808.

[8] H. Philipps, "Performance measurements of powerline channels at high frequencies," in Proceedings of International Symposium on Power-line Communications and its Applications, 1998, pp. 229-237.

[9] M. Zimmermann and K. Dostert, "A multipath model for the powerline channel," Communications, IEEE Transactions on, vol. 50, pp. 553-559, 2002.

[10] D. Anastasiadou and T. Antonakopoulos, "Multipath characterization of indoor power-line networks," Power Delivery, IEEE Transactions on, vol. 20, pp. 90-99, 2005.

[11] M. Zimmermann and K. Dostert, "Low voltage power distribution network as last mile access network- signal propagation and noise scenario in the HF-range," $A E U$ ARCH. ELEKTR. UBERTRAGUNGSTECHN, vol. 54, pp. 13-22, 2000.

[12] E. Guerrini, L. Guerrieri, D. Veronesi, P. Bisaglia, and R. Cappelletti, "LLR-based Bit-loading Algorithm and its Applications to HomePlug AV over OPERA Power-line Channels with Impulsive Noise," Journal of Communications, vol. 4, pp. 454-462, 2009.

[13] T. Fukami, D. Umehara, M. Kawai, and Y. Morihiro, "Noncoherent PSK optimum receiver over impulsive noise channels," in Proc. of the 2002 ISPLC Conf, 2002, pp. 235-238.

[14] C. Hsu, N. Wang, W.-Y. Chan, and P. Jain, "Improving a power line communications standard with LDPC codes," EURASIP Journal on Advances in Signal Processing, vol. 2007, p. 060839, 2007.

[15] C. S. Panda and S. Patnaik, "Filtering corrupted image and edge detection in restored grayscale image using derivative filters," International Journal of Image Processing (IJIP), vol. 3, pp. 105-119, 2009.

[16] I. Ku, "Robust multicarrier CDMA receiver for coded power-line communications," IEICE Electronics Express, vol. 6, pp. 347-353, 2009.

[17] L. Ahlin, J. Zander, and S. Ben Slimane, "Principles of wireless communications," 2006.

[18] J. A. Wepman, J. R. Hoffman, and L. H. Loew, "Impulse response measurements in the $1850-1990 \mathrm{MHz}$ band in large outdoor cells," NASA STI/Recon Technical Report $N$, vol. 95, p. 14412, 1994.

[19] T. S. Rappaport, Wireless communications: principles and practice vol. 2: prentice hall PTR New Jersey, 2002.

[20] G. L. Stüber, Principles of Mobile Communications, 2 ed. New York, USA: Kluwer Academic Publishers, 2002. 
[21] A. Ghosh, D. R. Wolter, J. G. Andrews, and R. Chen, "Broadband wireless access with WiMax/802.16: current performance benchmarks and future potential," Communications Magazine, IEEE, vol. 43, pp. 129-136, 2005.

[22] D. S. Shuabu, S. Kamilah, N. Faisal, and Y. S. Baguda, "Simulation and Performance Analysis of Partial Usage Subchannels in WiMAX IEEE802. 16e," International Journal of Recent Trend in Engineering Vol, vol. 2, pp. 126-129, 2009.

[23] W. Henkel, G. Taubock, P. Odling, P. O. Borjesson, and N. Petersson, "The cyclic prefix of OFDM/DMT-an analysis," in Broadband Communications, 2002. Access, Transmission, Networking. 2002 International Zurich Seminar on, 2002, pp. 22-1-22-3.

[24] A. Goldsmith, Wireless communications: Cambridge university press, 2005.

\section{APPENDIX: POWER-LINE CHANNEL MODEL USED}

The Equations.1-20[1] represents the power-line channel model based on Transmission Line Theory which has been used in this work to simulate power-line communication.

Transfer Function in frequency domain:

$\mathrm{H}_{\mathrm{nm}}(\mathrm{f})=$

$\frac{Z_{\mathrm{C} 11}+Z_{s}}{Z_{C 11}} Z_{C n m}\left(e^{-\gamma_{n m} L_{n m}} \beta_{n m}+e^{\gamma_{n m} L_{n m}}\right) A_{n m} \frac{1}{A_{1}^{+} \beta_{11}+A_{1}^{-}}(1)$

$\beta_{n n}=\frac{C_{n n}^{-}-P_{n} B_{n n}^{-}}{C_{n n}^{+}+P_{n} B_{n n}^{-}}$

$P_{n}=\frac{e_{n m}(1)}{a_{n m}(1)}+\frac{e_{n m}(2)}{a_{n m}(2)}$

Loads connected at various nodes:

$\beta_{\mathrm{nm}}=\frac{\left(1-\frac{z_{\mathrm{Cnm}}}{Z_{\mathrm{nm}}}\right) e^{-\gamma_{n m} \mathrm{~L}_{\mathrm{nm}}}}{\left(1+\frac{z_{\mathrm{nn}}}{Z_{\mathrm{nm}}}\right) \mathrm{e}^{\gamma_{n m} \mathrm{r}_{\mathrm{nm}}}}$

$A_{n m}=\frac{a_{n} a_{n-1} \ldots \ldots a_{1}}{a_{n m} a_{(n-1)(n)} a_{(a-2)(n-1) \cdots . . ~} a_{12}}$

$$
\begin{aligned}
& \mathrm{a}_{\mathrm{nm}}=\mathrm{B}_{\mathrm{mn}}^{+} \beta_{\mathrm{n}}+\mathrm{B}_{\mathrm{mn}}^{-} \\
& \mathrm{e}_{\mathrm{nm}}=\mathrm{C}_{\mathrm{mn}}^{-}-\mathrm{C}_{\mathrm{mn}}^{+} \beta_{\mathrm{n}} \\
& \beta_{\mathrm{n}}=\left\{\begin{array}{l}
\beta_{(\mathrm{n}+1)(\mathrm{n}+1)} \\
\beta_{\mathrm{nm}} \quad \text { to node } \mathrm{n}+1
\end{array}\right. \\
& \mathrm{a}_{\mathrm{mn}}=\mathrm{B}_{\mathrm{nm}}^{+} \beta_{\mathrm{nm}}+\mathrm{B}_{\mathrm{nm}}^{-} \\
& \mathrm{a}_{\mathrm{n}}=\mathrm{B}_{\mathrm{nn}}^{+} \beta_{\mathrm{nn}}+\mathrm{B}_{\mathrm{nn}}^{-} \\
& \mathrm{B}_{\mathrm{mn}}^{+}=\mathrm{Z}_{\mathrm{Cmn}} \mathrm{e}^{-\gamma_{\mathrm{mn}} \mathrm{L}_{\mathrm{n}}} \\
& \mathrm{B}_{\mathrm{mn}}^{-}=\mathrm{Z}_{\mathrm{Cmn}} \mathrm{e}^{\gamma_{\mathrm{mn}} \mathrm{L}_{\mathrm{n}}} \\
& \mathrm{B}_{\mathrm{nm}}^{+}=\mathrm{Z}_{\mathrm{Cnm}} \mathrm{e}^{-\gamma_{\mathrm{nm}} \mathrm{L}_{\mathrm{n}}} \\
& \mathrm{B}_{\mathrm{nm}}^{-}=\mathrm{Z}_{\mathrm{Cnm}} \mathrm{e}^{\gamma_{\mathrm{nm}} \mathrm{L}_{\mathrm{n}}} \\
& \mathrm{C}_{\mathrm{mn}}^{+}=\mathrm{e}^{-\gamma_{\mathrm{mn}} \mathrm{L}_{\mathrm{n}}} \\
& \mathrm{C}_{\mathrm{mn}}^{-}=\mathrm{e}^{\gamma_{\mathrm{mn}} \mathrm{L}_{\mathrm{n}}}
\end{aligned}
$$

At nodes:

$$
\begin{aligned}
& \mathrm{B}_{\mathrm{nn}}^{+}=\mathrm{Z}_{\mathrm{Cnn}} \mathrm{e}^{-\gamma_{n n} \mathrm{~L}_{\mathrm{n}}} \\
& \mathrm{B}_{\mathrm{nn}}^{-}=\mathrm{Z}_{\mathrm{Cnn}} \mathrm{e}^{\gamma_{n n} \mathrm{~L}_{\mathrm{n}}} \\
& \mathrm{C}_{\mathrm{nn}}^{+}=\mathrm{e}^{-\gamma_{n n} \mathrm{~L}_{n}} \\
& \mathrm{C}_{\mathrm{nn}}^{-}=\mathrm{e}^{\gamma_{n n} \mathrm{~L}_{\mathrm{n}}}
\end{aligned}
$$

In the equations, $\mathrm{ZCmn}, \mathrm{Znm}$, $\gamma \mathrm{nm}$, Lnm and $\mathrm{Ln}$ represents the characteristic impedance of line segment $\mathrm{nm}$, terminal load impedance of line segment $\mathrm{nm}$, propagation constant of line segment $\mathrm{nm}$, length of line segment $\mathrm{nm}$ and direct path length from the sending end to the node $\mathrm{n}$ under consideration, respectively. 